\title{
Knowledge and Determinants of Mother Kangaroo Care (MKC) at the Hospital Environment of Lubumbashi in DR Congo: About a Survey Carried out at Jason Sendwe Hospital
}

\author{
Sangwa Sinanduku Judith ${ }^{1,2}$, Abdala Kingwengwe Aimé1,3, Moma Franck, \\ Tamubango Kitoko Herman ${ }^{5}$, Kanteng A Wakamb Gray ${ }^{1}$, Mutombo Kabamba André6, \\ Luboya Numbi Oscar ${ }^{1}$, Wembonyama Okitotsho Stanis ${ }^{1}$
}

\author{
${ }^{1}$ Department of Pediatrics, University Clinics of Lubumbashi, University of Lubumbashi, Lubumbashi, Democratic Republic of \\ Congo (DR Congo) \\ ${ }^{2}$ Department of Pediatrics, Jason Sendwe Provincial Hospital, Lubumbashi, DR Congo \\ ${ }^{3}$ Department of Pediatrics, Faculty of Medicine, University of Kindu, Kindu, DR Congo \\ ${ }^{4}$ National Ministry of Public Health, Kinshasa, DR Congo \\ ${ }^{5}$ Higher Institute of Medical Techniques of Likasi, Kindu, DR Congo \\ ${ }^{6}$ Department of Pediatrics, Faculty of Medicine, Official University of Mbuji-Mayi, Mbuji-Mayi, DR Congo \\ Email: *aimeabdala@gmail.com
}

How to cite this paper: Judith, S.S., Aimé, A.K., Franck, M., Herman, T.K., Gray, K.A.W., André, M.K., Oscar, L.N. and Stanis, W.O. (2020) Knowledge and Determinants of Mother Kangaroo Care (MKC) at the Hospital Environment of Lubumbashi in DR Congo: About a Survey Carried out at Jason Sendwe Hospital. Open Access Library Journal, 7: e6360.

https://doi.org/10.4236/oalib.1106360

Received: April 25, 2020

Accepted: May 23, 2020

Published: May 26, 2020

Copyright $\odot 2020$ by author(s) and Open Access Library Inc.

This work is licensed under the Creative Commons Attribution International License (CC BY 4.0).

http://creativecommons.org/licenses/by/4.0/ (c) (i) Open Access

\begin{abstract}
The poor heat chain observed in developing countries remains an important risk factor for premature death. Mother Kangaroo care (MKC) presents itself as an efficient alternative for the improvement of the conditions for raising premature babies to a poorly equipped area. The objective of this study was to determine the level of knowledge of the MKC and to identify the factors influencing said knowledge. This was a qualitative survey-type study that involved 50 people met in the pediatrics department of Jason Sendwe Hospital from March $1^{\text {st }}$ to $31^{\text {st }}, 2018$. At the end of our analyzes, it comes out that $96 \%$ of people met had already been informed about the MKC method; only $42 \%$ of our respondents have a global knowledge of the MKC method; the age above 40 years old, the quality of a medical Doctor and the affectation to neonatology are the factors that are positively associated in an independent way with good knowledge of the method of MKC. The popularization of the MKC method must remain a priority in our under-equipped environments in order to considerably reduce neonatal mortality in general and the lethality of prematurity in particular.
\end{abstract}




\section{Subject Areas}

Nursing

\section{Keywords}

Mother-Kangaroo Care, Prematurity, Knowledge, Lubumbashi

\section{Introduction}

The neonatal mortality represents $47 \%$ of all the registered deaths around the age group under 5 years old. Reducing this mortality represents a WHO battle horse at 2030 horizon [1] [2].

Prematurity and its complications remain the main causes in both morbidity and neonatal mortality. A predisposing factor remains the poor heat chain especially observed in developing countries where the number and the operating incubators remain unsatisfying to the need [1] [2] [3] [4] [5].

To overcome the difficulties due to the usage of the electric incubators considered as the means of the heat chain during the raising of premature newborns, Mother Kangaroo Care method (MKC) has been proposed as the alternative for more than thirty years by one team of Colombian medical Doctors [6].

Mother Kangaroo Care method consists of making into contact skin on skin of the premature baby on his parent's chest in a early way, prolonged and continuous manner, in hospital environment or at home (if the said method has been taught and if there is a regular follow-up). This method has proven to be effective, gentle and simple to perform. It is ideally accompanied by exclusive breastfeeding which helps to reduce the premature baby's agitations and the period of hospitalization [7].

Despite the fact that Mother Kangaroo Care method is recognized as being effective, so many authors denote inequalities in its application all over the world [8].

Several factors seem to explain the low use of Mother Kangaroo Care at certain regions of the globe. Among them we can maintain the lack of adhesion to the said method, inaccessibility of some pregnant women to health services and the cultural influence. These factors concern families (mother, father and those around them), medical staff and the neonatal care infrastructures [8].

In the town city of Lubumbashi we noted that only $39 \%$ of premature babies were raised by the Mother Kangaroo Care method along a longitudinal study carried out from 2013 to 2015. The low rate was due to poor adhesion of actors involved on the implementation of this care. Those actors are primarily the laying in women and the medical stuff. This would be explained by a poor knowledge of this method in our environment [4].

With this observation, the present study has proposed to evaluate the level of knowledge of Mother Kangaroo Care method and to come out with certain de- 
terminants of this knowledge.

\section{Methodology}

Our study was conducted at the pediatrics service at Jason Sendwe Provincial Hospital. It is a $3^{\text {rd }}$ level health facility in the DR Congo healthcare system. It is located in Lubumbashi town city with the vocation of the Referential Provincial General Hospital.

It was a qualitative survey-type study that involved 50 people met at the pediatrics service of Jason Sendwe Hospital from the $1^{\text {st }}$ to the $31^{\text {st }}$ of March, 2018. The sample size has been fixed for convenience since this study is only preliminary in our environment.

A questionnaire was submitted to all the respondents after its pre-test submitted to the trainee doctors at the University Clinics of Lubumbashi.

In order to collect data, the questionnaire was subdivided into three orders.

1) The socio professional characteristics of the respondent: age, sex, quality (medical doctor, Trainee doctor, Nurse, Mother) and the respondent belonging to neonatology unit.

2) The exposition to the information about Mother Kangaroo Care method.

3) Answers related to knowledge on Mother Kangaroo Care method.

Each participant was free to be part of the respondents by his own consent in order to clarify the investigation.

Mother Kangaroo Care method consists of making into contact skin on skin of the premature baby on his parent's chest in a early way, prolonged and continuous manner, in hospital environment or at home [7].

The collected data was treated by SPSS21 software. The descriptive statistics was applied with calculation of the simple percentage. The analytical statistics has been realized by dividing the respondents into two groups; those who know the Mother Kangaroo Care method and those who do not know anything about it. The comparisons between the two groups have been done according to the case, with the help of the test T-Student for quantitative variables, the Chi-Square test or Fisher's exact test for categorical variables.

The calculation of the adjusted odd ratio allowed us to estimate the association between the socio professional characteristics of the respondents and their level of knowledge of Mother Kangaroo Care method.

This study was carried out within the framework of a vast research which has already received a favorable opinion from the Ethics Committee of the University of Lubumbashi.

\section{Results}

We presented our questionnaire to 50 participants who accepted to answer it. $78 \%$ among them were of female sex compared to $22 \%$ of male sex. $52 \%$ were between 30 to 39 years old followed by $32 \%$ who were 40 years old and more and only $16 \%$ were under 30 years old (Table 1 ). 
Table 1. Respondents' socio-cultural characteristics.

\begin{tabular}{|c|c|c|}
\hline Variables & $\mathrm{N}=\mathbf{5 0}$ & $\%$ \\
\hline \multicolumn{3}{|l|}{ Age } \\
\hline$<30$ years old & 8 & 16.0 \\
\hline 30 - 39 years old & 26 & 52.0 \\
\hline $40-49$ years old & 16 & 32.0 \\
\hline \multicolumn{3}{|l|}{ Gender } \\
\hline Female & 39 & 78.0 \\
\hline Male & 11 & 22.0 \\
\hline \multicolumn{3}{|l|}{ Quality } \\
\hline Nurse & 20 & 40.0 \\
\hline Medical doctor & 15 & 30.0 \\
\hline Trainee doctor & 10 & 20.0 \\
\hline Mother & 5 & 10.0 \\
\hline \multicolumn{3}{|l|}{ Unit home } \\
\hline Neonatalogy & 27 & 54.0 \\
\hline Pediatric emergency & 16 & 32.0 \\
\hline Maternity & 5 & 10.0 \\
\hline Nutrition & 2 & 4.0 \\
\hline
\end{tabular}

Forty percent of the respondents were nurses, 30\% were Medical Doctors, $20 \%$ were Trainee Doctors and mothers represented 10\% (Table 1).

Fifty-two percent of our respondents were in the neonatology unit, $32 \%$ at the pediatric emergencies, $10 \%$ at the maternity and $4 \%$ at the nutritional unit (Table 1).

As far as the exposing of the information on Mother Kangaroo Care is concerned, $96 \%$ of our respondents are informed on Mother Kangaroo Care against only $4 \%$ who are not aware of this care (Figure 1 ).

Fifty-eight percent of our respondents do not have a general knowledge of Mother Kangaroo Care method against $42 \%$ who have the global knowledge of this method (Figure 2).

A significant difference was also observed between the respondents who know (12\%) the type of newborn eligible to Mother Kangaroo Care and those who do not know (88\%) (Table 2).

A significant difference was also observed between those who know (72\%) the precautions to be taken before the instauration of Mother Kangaroo Care method and those who do not know (28\%).

No significant difference was observed among those who know and those who do not know the advantages of Mother Kangaroo Care for new born 36\% vs. $32 \%$ ) for the mother ( $50 \%$ vs. $50 \%$ ), the contraindications of Mother Kangaroo Care ( $42 \%$ vs. $58 \%$ ), the duration of Mother Kangaroo Care (62\% vs. $32 \%)$ and 


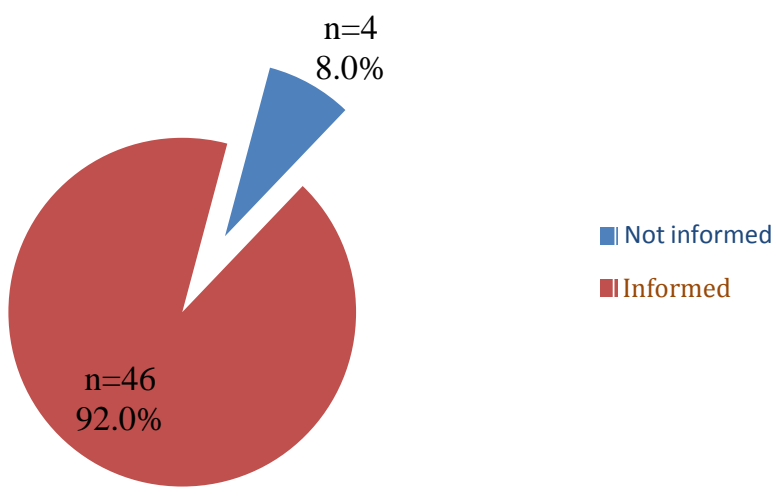

Figure 1. Distribution of respondents according to exposure to information on the MKC.
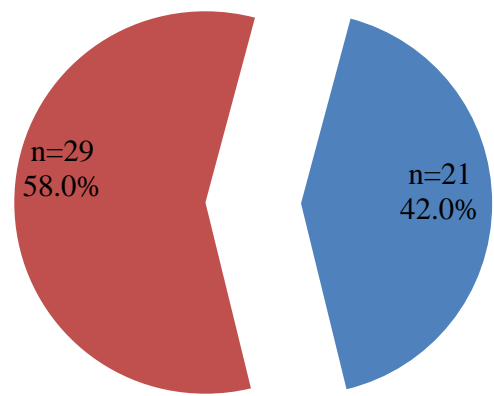

Knows the method

Don't know the method

Figure 2. Distribution of respondents according to their knowledge of the method MKC.

Table 2. Specific knowledge on MKC.

\begin{tabular}{cccc}
\hline Type of Knowledge & $\begin{array}{c}\text { Know } \\
\mathbf{n}(\%)\end{array}$ & $\begin{array}{c}\text { Know nothing } \\
\mathbf{n}(\%)\end{array}$ & P \\
\hline Type type of premature babies aligible to MSK & $6(12.0)$ & $44(88.0)$ & $<0.001$ \\
Precautions before MKC & $36(72.0)$ & $14(28.0)$ & $\mathbf{0 . 0 0 3}$ \\
Avantage of MKC for premature babies & $18(36.0)$ & $32(64.0)$ & 0.065 \\
Avantages for mothers & $25(50.0)$ & $25(50.0)$ & 0.999 \\
Contraindications of MKC & $21(42.0)$ & $29(58.0)$ & 0.322 \\
The practice duration & $31(62.0)$ & $19(38.0)$ & 0.119 \\
The place where to practice MKC & $32(64.0)$ & $18(36.0)$ & 0.065 \\
\hline
\end{tabular}

the place where Mother Kangaroo Care must be performed (64\% vs. 36\%) (Table 2).

In bi-varied analysis, the global knowledge on the Mother Kangaroo Care method was significantly higher among the interviewers of 40 to 49 years old (81.3\% vs. 23.5\%); for the Medical Doctors and nurses (66.7\% and 50\% respectively vs. $6.7 \%$ trainee Doctors and mothers) and for interviewers belonging on neonatology (66.7\% vs. $13 \%$ other units) (Table 3 ).

After adjustment, the age $\geq 40$ (ORa: $7.55 ; 1.5$ - 9.2); the quality of a medical Doctor (ORa: 5.66; IC95\%: 2.42 - 7.61); nurse (2.47; IC\%: 1.06 - 3.99) and the fact of belonging in a neonatology unit (ORa: 7.79; IC95\%: 2.68 - 9.4) were the 
Table 3. Associated factors for the global knowledge on MKC.

\begin{tabular}{|c|c|c|c|c|}
\hline \multirow[b]{2}{*}{ Variables } & \multicolumn{2}{|c|}{ Global knowledge } & \multirow[b]{2}{*}{ ORa (IC95\%) } & \multirow[b]{2}{*}{$\mathbf{P}$} \\
\hline & $\begin{array}{c}\text { yes } \\
\text { n (\%) }\end{array}$ & $\begin{array}{c}\text { No } \\
\text { n (\%) }\end{array}$ & & \\
\hline \multicolumn{5}{|l|}{ Age } \\
\hline$<40$ years old & $8(23.5)$ & $26(76.5)$ & 1 & \\
\hline 40 - 49 years old & $13(81.3)$ & $3(18.8)$ & $7.55(1.5-9.26)$ & $<0.001$ \\
\hline \multicolumn{5}{|l|}{ Gender } \\
\hline Male & $4(36.4)$ & $7(63.6)$ & 1 & \\
\hline Female & $17(43.6)$ & $22(56.4)$ & $1.42(0.26-2.43)$ & 0.741 \\
\hline \multicolumn{5}{|l|}{ Quality } \\
\hline trainee and Mother & $1(6.7)$ & $14(93.3)$ & 1 & \\
\hline Nurse & $10(50.0)$ & $10(50.0)$ & $2.47(1.06-3.99)$ & 0.003 \\
\hline Medical doctor & $10(66.7)$ & $5(33.3)$ & $5.66(2.42-7.61)$ & 0.002 \\
\hline \multicolumn{5}{|l|}{ Unit home } \\
\hline Others & $3(13.0)$ & $20(87.0)$ & 1 & \\
\hline Neonatology & $18(66.7)$ & $9(33.3)$ & $7.79(2.68-9.94)$ & $<0.001$ \\
\hline
\end{tabular}

factors independently associated to the right knowledge on Mother Kangaroo Care method (Table 3).

\section{Discussion}

Our study focused on the restricted sample. Its results cannot therefore be generalized to the population of Lubumbashi.

Our investigation has shown that $96 \%$ of the respondents we met have already been informed about Mother Kangaroo Care method. We have not found the regional or continental study which has evaluated this parameter. The result observed in our study is the fruit of sensitization carried out at this hospital since 2013 in the context of the introduction of Mother Kangaroo Care on the program of raising premature babies.

Our results show that only $42 \%$ of our respondents have the global knowledge of Mother Kangaroo Care method. This rate is inferior to that observed in the study carried out in France where more than $70 \%$ of the respondents had the correct global knowledge on Mother Kangaroo Care [9]. On the other hand, our results are higher than those observed in Ahmedabad where only $32 \%$ of respondents had a correct overall knowledge of MKC [10]. On the other hand, our results are higher than those observed in Ahmedabad where only $32 \%$ of respondents had a correct overall knowledge of MKC. The tendency of our results represents a massive restriction of different categories of actors to adhere to this care in our area.

Much effort is to be provided in our area in the vulgarization and the sensitization on to Mother Kangaroo Care. The integration of its range in prenatal 
consultation activities and continuing education in neonatology would be the ideal.

Our study show that the medical stuff of the hospital (medical Doctors and nurses) have significantly high knowledge on Mother Kangaroo Care compared to mothers and the trainee Doctors. The same observation was made between the people we met in neonatology and those we met in other units and departments. It is the result of a prolonged exposition of the information and practice on Mother Kangaroo Care that would explain these differences. This experience must be capitalized by recommending the Constancy of the affectation of the personnel in different units and particularly the neonatology. Spurious rotations can negatively influence this achievement.

In our series, the age superior to 40 years old, the quality of a medical Doctor and the affectation to neonatology are the factors that are positively associated in an independent way with good knowledge of the method of MKC. This result is close to the observation made by Dalal [10]. This observation allows us to identify the resource persons when there is need to come up with the program of vulgarization and sensitization on Mother Kangaroo Care method in our area.

\section{Conclusion}

Our study provides satisfactory level of information on Mother Kangaroo Care method. But we can observe a contrast between the level of information and the level of the knowledge of the said method which is still unsatisfactory. Other more elaborated works must be carried out in our area as for attitude, the practice, and the deep knowledge of Mother Kangaroo Care with different categories of population of Lubumbashi.

\section{The Contribution of the Study}

This study helped us to identify certain factors that positively influence the knowledge of Mother Kangaroo Care at Lubumbashi.

\section{Authors Contribution}

The authors contributed proportionally to the tasks they assigned to themselves at the beginning of the study.

\section{Conflicts of Interest}

The authors declare no conflict of interest.

\section{References}

[1] OMS. Nouveau-nés: Réduire la mortalité https://www.who.int/fr/news-room/fact-sheets/detail/newborns-reducing-mortality

[2] OMS WHO Supports the Immunization of 874000 People against Yellow Fever in Nigeria 7000 Newborns Die Every Day, Despite Steady Decrease in under-Five Mortality, New Report Says. 
[3] Abdala, K.A., Shindano, M.E., Lukusa, P.M., Nyenga, M.A., Katamea, T., Assumani, N., et al. (2019) Morbi-mortalité néonatale à l'hôpital général de référence de Kindu. Etat de lieux et perspectives. Médecine d’ Afrique noire électronique, 10.

[4] Sangwa, S.J., Kanteng, G., Moma, F., Okitotsho, S.W. and Luboya, O. (2019) Management of Premature Infants Using the Kangaroo Method versus the Classic Method: Morbidity and Prognosis Associated with in Sendwe General Hospital in Lubumbashi (DR Congo). Open Access Library Journal, 6, 1-13.

https://doi.org/10.4236/oalib.1105150

[5] Nyenga, A.M. (2019) Trends in Neonatal Mortality in Lubumbashi (Democratic Republic of Congo) from 2011 to 2018. Pediatric Surgery, 2, 5.

[6] Garnier, G., Piccot Crezollet, M. and Reynier, P. (2018) La méthode kangourou et les facteurs liés à la triade bébé-parents-infirmier influençant son application en néonatologie. $\mathrm{PhD}$ Thesis, Haute école de santé, Genève.

[7] OMS. Arrivés trop tôt: Rapport des efforts mondiaux portant sur les naissances prématurées.

https://www.who.int/maternal child adolescent/documents/born too soon/fr/

[8] Chan, G.J., Labar, A.S., Wall, S. and Atun, R. (2016) Kangaroo Mother Care: A Systematic Review of Barriers and Enablers. Bulletin of the World Health Organization, 94, 130-141. https://doi.org/10.2471/BLT.15.157818

[9] Mallet, I., Bomy, H., Govaert, N., Goudal, I., Brasme, C., Dubois, A., et al. (2007) Le peau à peau en médecine néonatale: Connaissances et attentes des professionnels de santé dans deux unités de néonatologie de niveau III. Archives de Pédiatrie, 14, 881-886. https://doi.org/10.1016/j.arcped.2007.01.017

[10] Dalal, A., Bala, D.V. and Chauhan, S. (2014) A Cross-Sectional Study on Knowledge and Attitude Regarding Kangaroo Mother Care Practice among Health Care Providers in Ahmedabad District. International Journal of Medical Science and Public Health, 3, 253-256. https://doi.org/10.5455/ijmsph.2013.091220131 


\section{Appedix (Abstract and keywords in French)}

\section{Résumé}

La mauvaise chaîne de chaleur observée dans les pays en développement reste un facteur important de risque de décès de prématurés. Les soins mère-kangourou se présentent comme une alternative efficiente à l'amélioration des conditions d'élevage des prématurés en milieu sous ou mal équipé. L'objectif de cette étude était de déterminer le niveau de connaissance des SMK et d'identifier les facteurs influençant la dite connaissance.

Il s'est agi d'une étude qualitative de type enquête qui a concerné 50 personnes rencontrées dans le service de pédiatrie de l'hôpital Jason Sendwe du $1^{\text {er }}$ au 31 mars 2018.

A l'issue de nos analyses, il ressort que $96 \%$ de personnes rencontrées avaient déjà été informées sur la méthode de SMK; seulement $42 \%$ de nos enquêtés ont une connaissance globale sur la méthode de SMK; l'âge supérieur à 40 ans, la qualité de Médecin et l'affectation en néonatologie sont les facteurs positivement associés de manière indépendante à une bonne connaissance de la méthode de SMK.

La vulgarisation de la méthode des SMK doit rester une priorité dans nos milieux sous équipés afin de réduire considérablement la mortalité néonatale en générale et la létalité de la prématurité en particulier.

Mots-clés: Soins mère-kangourou, prématurité, connaissance, Lubumbashi. 